\title{
Epigallocatechin-3-gallate suppresses cell proliferation and promotes apoptosis in Ec9706 and Eca109 esophageal carcinoma cells
}

\author{
LIANG LIU, JING ZUO and GUANGDA WANG \\ Department of Flow Cytometry Analysis, Tumor Institute, \\ The Fourth Hospital of Hebei Medical University, Shijiazhuang, Hebei 050011, P.R. China
}

Received October 23, 2015; Accepted March 21, 2017

DOI: $10.3892 / \mathrm{ol} .2017 .6712$

\begin{abstract}
Epigallocatechin-3-gallate (EGCG) is a component of green tea with anticancer effects that have been demonstrated in multiple types of cancer, but few reports exist concerning its effect in esophageal squamous cell carcinoma cells. The present study investigated apoptosis induced by EGCG treatment and the underlying molecular mechanisms in Eca109 and Ec9706 human esophageal squamous cell carcinoma cells. The apoptosis rate following treatment with various concentration of EGCG for $24 \mathrm{~h}$ was detected by flow cytometry. The effect of EGCG on esophageal cancer cell viability was detected via MTT assay. Mitochondrial membrane potential and caspase-3 protein expression was detected in Eca109 and Ec9706 cells following treatment with EGCG by flow cytometry. The telomerase activity of Eca109 and Ec9706 cells following treatment with EGCG was assayed using the polymerase chain reaction-telomeric repeat amplification protocol (PCR-TRAP) argentation method. EGCG was demonstrated to inhibit the viability of Eca109 and Ec9706 cells in a dose-and time-dependent manner. The flow cytometry results revealed that EGCG treatment induced apoptosis, decreased the mitochondrial membrane potential and increased caspase- 3 protein expression levels. PCR-TRAP argentation analysis revealed that EGCG inhibited telomerase activity. The results of the present study suggested that EGCG functions as an antitumor agent in esophageal cancer cells. The induction of apoptosis may be a viable method for treating esophageal cancer. It is possible to induce apoptosis by modulating the expression level of telomerase activity,
\end{abstract}

Correspondence to: Dr Liang Liu, Department of Flow Cytometry Analysis, Tumor Institute, The Fourth Hospital of Hebei Medical University, 12 Jiankang Road, Shijiazhuang, Hebei 050011, P.R. China

E-mail: aliangdaziran@163.com

Key words: esophageal squamous cell carcinoma, flow cytometry, epigallocatechin-3-gallate, mitochondrial membrane potential mitochondrial membrane potential and caspase-3 protein expression levels.

\section{Introduction}

Esophageal squamous cell carcinoma is a common malignant tumor (1-3). The initiation and progression of esophageal cancer is a complicated process that results from the loss of the normal regulatory pathways controlling cell proliferation, differentiation and apoptosis. However, present therapeutic strategies, including chemotherapy, are characterized by low efficacies (4). Drug resistance and side effects of chemotherapy drugs are major barriers to the success of chemotherapy (5). Therefore, the identification of novel drugs for use in chemotherapy against esophageal squamous cell carcinoma is required (6).

Certain natural products have been suggested to be effective agents for cancer prevention, including epigallocatechin-3-gallate (EGCG). EGCG is the ester form of epigallocatechin/gallic acid; it is the main catechin in green tea and contributes to its beneficial therapeutic effects, which include antioxidant and immunomodulatory effects (7-10). Due to its reported anti-oxidant and immunomodulatory effects, EGCG has been extensively investigated against various types of cancer (11-13). EGCG has not been observed to cause adverse effects against normal cells and tissues, whereas it has anti-proliferative, anti-invasive and chemo-preventive effects against cancer cells (14). However, the number of investigations concerning the effect of EGCG on esophageal cancer is limited, and the potential function of EGCG in esophageal cancer therapy remains poorly understood. Cell growth and apoptosis are regulated through complex signaling systems in the human body; their disorder or imbalance may induce the development of tumors (15). The efficacy of chemotherapy drugs can be evaluated by their ability to induce apoptosis. The upregulation of caspase- 3 and the reduction of mitochondrial membrane potential may result in apoptosis, so an ideal chemotherapy drug would cause these alterations $(16,17)$.

The present study investigated the anticancer effects of EGCG in esophageal squamous cell carcinoma and the underlying molecular mechanisms in human esophageal squamous cell carcinoma cells. 


\section{Materials and methods}

Cancer cell lines and culture. Human esophageal Eca109 cancer cells were obtained from the Cancer Institution, The Fourth Hospital of Hebei Medical University (Shijiazhuang, China). Human esophageal Ec9706 cancer cells were obtained from the Molecular Oncology State Key Laboratory Cancer Institute and Hospital of the Chinese Academy of Medical Sciences (Beijing, China).

Cells were cultured in RPMI-1640 medium supplemented with 10\% fetal bovine serum (both from Gibco; Thermo Fisher Scientific, Inc., Waltham, MA, USA), $100 \mathrm{U} / \mathrm{ml}$ penicillin and $100 \mu \mathrm{g} / \mathrm{ml}$ streptomycin at $37^{\circ} \mathrm{Cin}$ a humidified atmosphere of $5 \% \mathrm{CO}_{2}$.

Chemicals and reagents. EGCG was purchased from Sigma-Aldrich (Merck KGaA, Darmstadt, Germany). The Annexin V-fluorescein isothiocyanate (FITC)/propidium iodide (PI) kit was purchased from Beckman Coulter, Inc. (Brea, CA, USA). Mouse anti-human caspase-3 monoclonal antibodies (cat. no. sc-7272) were purchased from Santa Cruz Biotechnology, Inc. (Dallas, TX, USA). FITC-conjugated goat anti-mouse secondary IgG antibody (cat. no., 115-095-003) was purchased from Jackson Immuno Research Laboratories, Inc. (West Grove, PA, USA).

Cytotoxicity assay. The sensitivity of Eca109 and Ec9706 cells to EGCG was determined using an MTT assay, in which the capacity of viable cells to metabolize MTT reagent salt to purple formazan crystals via mitochondrial succinate dehydrogenase was assessed. Cells were seeded into 96-well culture plates at a density of $5 \times 10^{4}$ cells $/ \mathrm{ml}$. Serial concentrations of EGCG $(0$, $25,50,100,200$ and $400 \mathrm{mg} / \mathrm{l}$ ) were added in a final volume of $200 \mu \mathrm{l}$ per well. Following treatment for 24 or $48 \mathrm{~h}$ at $37^{\circ} \mathrm{C}$, the medium was replaced with an equal volume of fresh medium containing $0.5 \mathrm{mg} / \mathrm{ml}$ MTT (Sigma-Aldrich; Merck KGaA) and incubated for $4 \mathrm{~h}$. Then, the medium was removed and $180 \mu \mathrm{l}$ DMSO was added and incubated for $10 \mathrm{~min}$ at room temperature. The cytotoxic effects of drugs were determined according to the OD values using a microplate reader at an absorption wavelength of $490 \mathrm{~nm}$. Cell viability was expressed as the relative formazan formation in treated samples when compared with control cells: Growth inhibitory rate $=[(1-\mathrm{A} 490$ treated cells/A490 control cells)x100\%].

Apoptosis analysis. Cultured Eca109 and Ec9706 tumor cells treated with $0,100,200$ or $300 \mathrm{mg} / 1 \mathrm{EGCG}$ for $24 \mathrm{~h}$ at $37^{\circ} \mathrm{C}$ were harvested. The cells $\left(1 \times 10^{6}\right)$ were stained with PI and Annexin V-FITC, according to the manufacturer's protocol and analyzed using an Epics-XL flow cytometer (Beckman Coulter, Inc.). Expo32 v1.2 software (Beckman Coulter, Inc.) was used to analyze the flow cytometric data. Early apoptotic cells were positive for Annexin V and negative for PI staining, whereas late apoptotic cells undergoing secondary necrosis were positive for Annexin V and PI staining.

Analysis of mitochondrial membrane potential expression level in Eca109 and Ec9706 cells. Cultured Eca109 and Ec9706 tumor cells $\left(1 \times 10^{6}\right)$ were harvested following treatment with $0,100,200$ or $300 \mathrm{mg} / \mathrm{l} \mathrm{EGCG}$ for 24 hat $37^{\circ} \mathrm{C}$.
Following two washes with ice-cold PBS, the cells were dyed in $1 \mathrm{ml}$ of $10 \mu \mathrm{g} / \mathrm{ml}$ Rhodamine 123 dissolved in distilled water. Following incubation for $30 \mathrm{~min}$ in the dark at $37^{\circ} \mathrm{C}$ and two washes with ice-cold PBS, the stained cells were resuspended in $1 \mathrm{ml}$ PBS. The stained cells were analyzed using an Epics-XL flow cytometer. Expo32 v1.2 software was used to analyze the flow cytometric data.

Analysis of caspase-3 protein. Cultured Eca109 and Ec9706 tumor cells $\left(1 \times 10^{6}\right)$ were harvested following treatment with 0, 100, 200 or $300 \mathrm{mg} / 1 \mathrm{EGCG}$ for $24 \mathrm{~h}$ at $37^{\circ} \mathrm{C}$. Cells were fixed overnight with $70 \%$ ice-cold ethanol. Following two washes with ice-cold PBS, the fixed cells were resuspended in $1 \mathrm{ml}$ PBS containing caspase-3 antibody (dilution, 1:100) and incubated for $30 \mathrm{~min}$ in the dark at room temperature. Following two washes with PBS, cells were resuspended in $1 \mathrm{ml}$ PBS containing secondary FITC-conjugated immunoglobulin $\mathrm{G}$ antibodies and incubated for $30 \mathrm{~min}$ in the dark at room temperature. An isotype control group with no primary antibody was used to exclude nonspecific binding. Following two washes with PBS, cells were resuspended in $1 \mathrm{ml}$ PBS. The stained cells were analyzed using an Epics-XL type flow cytometer. Expo32 v1.2 software was used to analysis the flow cytometric data.

Analysis of telomerase activity. Telomerase activity was determined using a telomeric repeat amplification protocol silver staining kit (cat. no. GMS 20106.1C.1; Genmed Scientifics, Inc., Shanghai, China) according to the manufacturer's protocol. Subsequent to silver staining, a positive outcome was bands with a 6 bp interval. Cultured Eca109 and Ec9706 tumor cells $\left(1 \times 10^{6}\right)$ were harvested following treatment with 0 , 100,200 or $300 \mathrm{mg} / \mathrm{EGCG}$ for $24 \mathrm{~h}$ at $37^{\circ} \mathrm{C}$, then telomerase activity was detected.

Statistical analysis. All data were presented as the mean \pm standard deviation and were statistically analyzed using a one-way analysis of variance followed by the Newman-Keuls method for post hoc comparisons, using SPSS 11.5 software (SPSS Inc., Chicago, IL, USA). $\mathrm{P}<0.05$ was considered to indicate a statistically significant difference.

\section{Results}

Inhibitory effect of EGCG on Eca109 and Ec9706 cells. The effect of EGCG on the viability of Eca109 and Ec9706 cells was analyzed by MTT assay. The viability of Eca109 and Ec9706 cells was significantly inhibited by EGCG in a dose and time dependent manner (Fig. 1).

EGCG induced esophageal cancer cell apoptosis. Experiments were performed using Eca109 and Ec9706 human esophageal cancer cells. Exposure to EGCG for $24 \mathrm{~h}$ was demonstrated to induce apoptosis in a dose-dependent manner in Eca109 and Ec9706 cells. Annexin V/PI staining revealed that EGCG treatment induced apoptosis in the range of 100 to $300 \mathrm{mg} / \mathrm{l}$ (Fig. 2).

EGCG modulates Eca109 and Ec9706 cell mitochondrial membrane potential. Eca109 and Ec9706 cells were treated with $0,100,200$ or $300 \mathrm{mg} / \mathrm{l}$ EGCG for $24 \mathrm{~h}$, washed with 


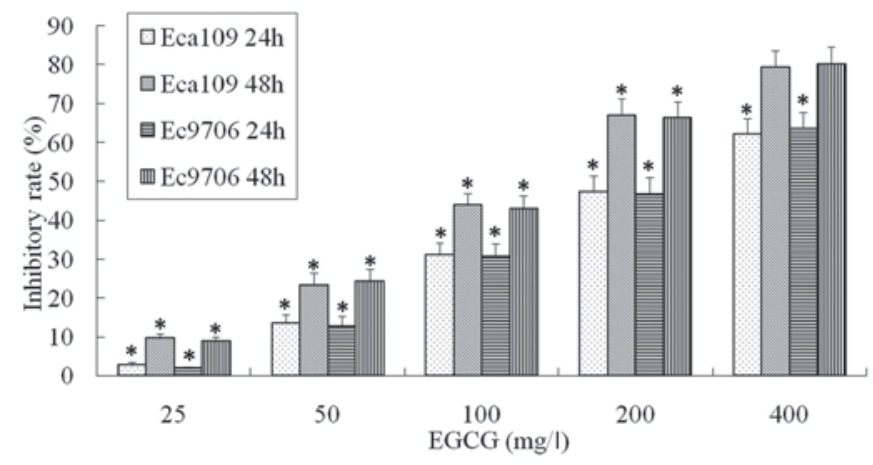

Figure 1. Inhibitory effect of EGCG on Eca109 and Ec9706 cells, as assessed by MTT assay. The viability of Eca109 and Ec9706 cells was significantly inhibited by EGCG in a dose and time dependent manner. ${ }^{*} \mathrm{P}<0.05$ vs. $400 \mathrm{mg} / \mathrm{l} \mathrm{EGCG} 48 \mathrm{~h}$ group. EGCG, epigallocatechin-3-gallate.

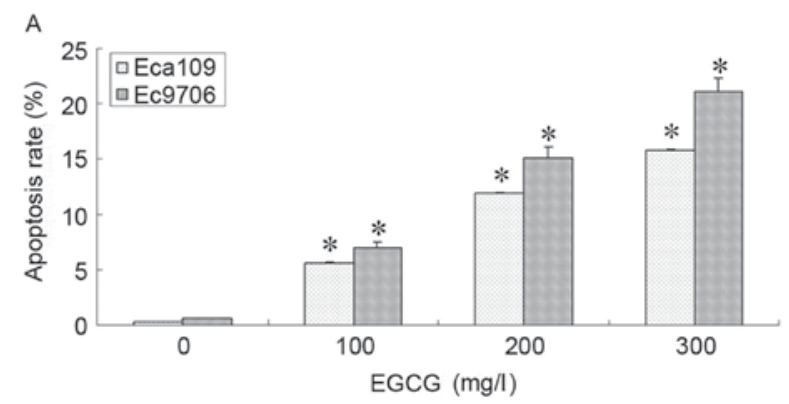

B
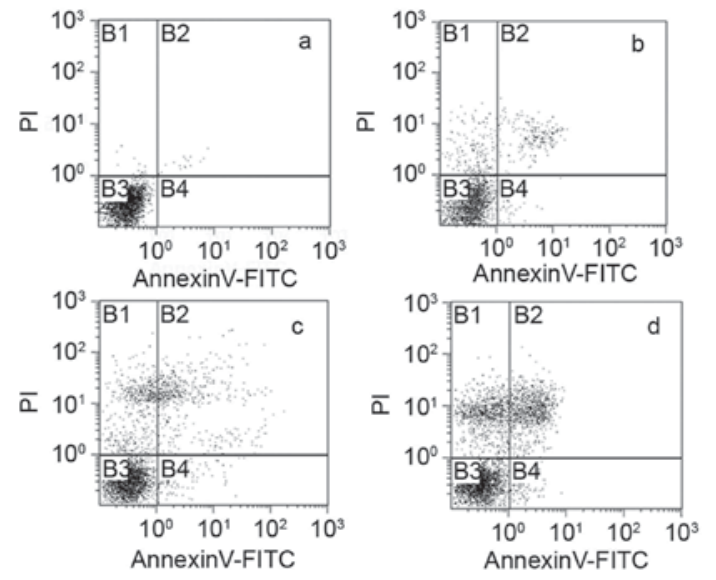

Figure 2. Eca109 and Ec9706 cell apoptosis following treatment with 100, 200 or $300 \mathrm{mg} / 1$ EGCG. (A) Apoptosis rate of Eca109 and Ec9706 cells following EGCG treatment. (B) Apoptosis rate of Ec9706 cells following treatment with EGCG for $24 \mathrm{~h}$, detected by flow cytometry. a, control group; b, 100 mg/lEGCG group; c, 200 mg/l EGCG group; and d, 300 mg/l EGCG group. "P $<0.05$ vs. $0 \mathrm{mg} / 1$ EGCG group of that cell type. EGCG, epigallocatechin-3-gallate; FITC, fluorescein isothiocyanate; PI, propidium iodide.

cold PBS, and flow cytometry was used to analyze the mitochondrial membrane potential. The mitochondrial membrane potential in the EGCG-treated groups was significantly lower compared with the control group ( $\mathrm{P}<0.01 ;$ Fig. 3). The $300 \mathrm{mg} / 1$ EGCG group had significantly lower mitochondrial membrane potential compared with the100 and $200 \mathrm{mg} / \mathrm{l}$ EGCG groups (P<0.01; Fig. 3).

Caspase-3 expression levels were increased following EGCG treatment in Eca109 and Ec9706 cells. Eca109 and Ec9706 cells were treated with $0,100,200$ or $300 \mathrm{mg} / \mathrm{l} \mathrm{EGCG}$ for $24 \mathrm{~h}$,

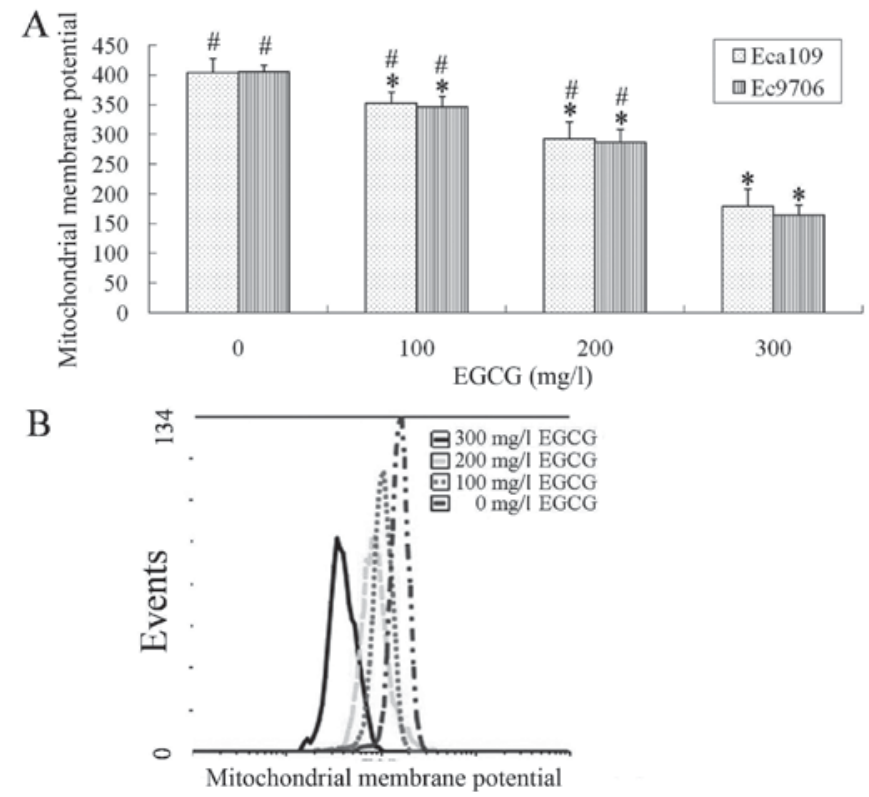

Figure 3. Mitochondrial membrane potential of Eca109 and Ec9706 cells following treatment with EGCG. (A) Mitochondrial membrane potential of the EGCG group was significantly lower compared with the control group. (B) Mitochondrial membrane potential of Ec9706 cells following treatment with 100,200 or $300 \mathrm{mg} / 1$ EGCG, detected by flow cytometry. ${ }^{*} \mathrm{P}<0.01$ vs. $0 \mathrm{mg} / 1 \mathrm{EGCG}$ group; ${ }^{\text {P }}<0.01$ vs. $300 \mathrm{mg} / 1 \mathrm{EGCG}$ group of that cell type. EGCG, epigallocatechin-3-gallate.

washed with cold PBS, and caspase-3 protein expression was analyzed using flow cytometry. Caspase-3 protein expression level was significantly upregulated in the treatment groups compared with the controls $(\mathrm{P}<0.05$; Fig. 4). Additionally, caspase-3 protein expression level was significantly higher in the $300 \mathrm{mg} / \mathrm{l}$ EGCG group compared with the 100 and $200 \mathrm{mg} / \mathrm{l}$ EGCG groups $(\mathrm{P}<0.05)$.

EGCG inhibited telomerase activity in Eca109 and Ec9706 cells. Following treatment with 100,200 or $300 \mathrm{mg} / \mathrm{l} \mathrm{EGCG} \mathrm{for}$ $24 \mathrm{~h}$, the telomerase activity in Eca109 and Ec9706 cells was significantly inhibited compared with control cells $(\mathrm{P}<0.05$; Fig. 5). Additionally, telomerase activity was significantly lower in the $300 \mathrm{mg} / \mathrm{l} \mathrm{EGCG}$ group compared with the 100 and $200 \mathrm{mg} / \mathrm{l}$ EGCG groups $(\mathrm{P}<0.05)$.

\section{Discussion}

EGCG is the most abundant catechin in green tea, and it possesses anti-inflammatory, antioxidant, immunomodulatory and anticancer functions (18-20). Previous studies have suggested that EGCG is associated with the potential health benefits attributed to green tea consumption (21). The anticancer effect of EGCG has been explored in various tumor cells (22-24), but there are few articles concerning the anticancer effect of EGCG on esophageal cancer. In the present study, EGCG was demonstrated to suppress the viability of esophageal cancer Eca109 and Ec9706 cells via inducing apoptosis in an EGCG dose-dependent manner. EGCG has been reported to induce cancer cell apoptosis through different pathways involving the pro-oxidant, epigenetic modulation of apoptosis-related genes, including human telomerase reverse 

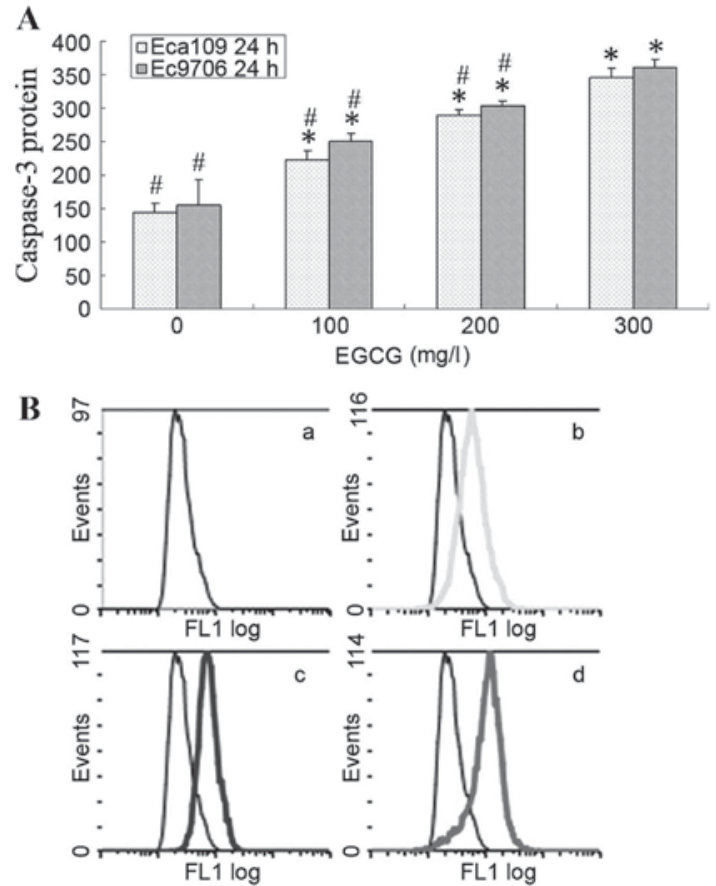

Figure 4. Caspase-3 protein expression of Eca109 and Ec9706 cells following treatment with EGCG. (A) Caspase-3 protein expression levels of the EGCG group were significantly increased compared with the control group. (B) Caspase-3 protein expression following treatment with 100, 200 or $300 \mathrm{mg} / 1$ EGCG was detected by flow cytometry. a, control group; b, $100 \mathrm{mg} / 1$ EGCG group; c, $200 \mathrm{mg} / 1$ EGCG group; and d, $300 \mathrm{mg} / 1$ EGCG group. ${ }^{*} \mathrm{P}<0.05$ vs. $0 \mathrm{mg} / 1 \mathrm{EGCG}$ group; ${ }^{\sharp} \mathrm{P}<0.05$ vs. $300 \mathrm{mg} / 1 \mathrm{EGCG}$ group of that cell type. EGCG, epigallocatechin-3-gallate; FL1, fluorescencechannel 1.

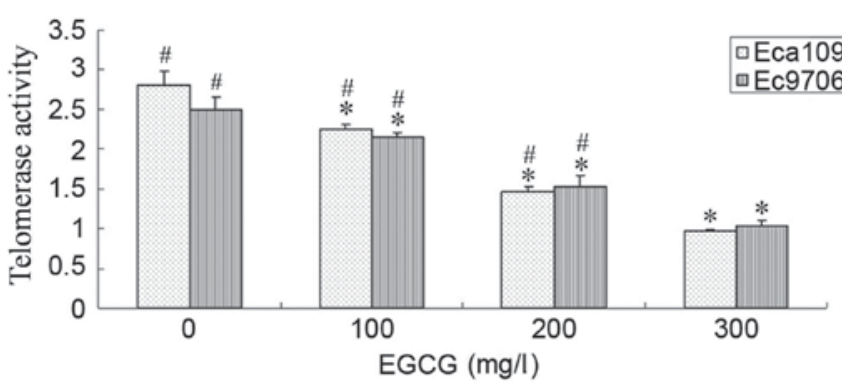

Figure 5. EGCG inhibited telomerase activity in Eca109 and Ec9706 cells. ${ }^{*} \mathrm{P}<0.05$ vs. $0 \mathrm{mg} / 1 \mathrm{EGCG}$ group; ${ }^{*} \mathrm{P}<0.05$ vs. $300 \mathrm{mg} / 1 \mathrm{EGCG}$ group of that cell type. EGCG, epigallocatechin-3-gallate.

transcriptase, and to reduce cell proliferation through the modulation of cell cycle progression (25-27).

In the present study, two esophageal cancer cell lines, Eca109 and Ec9706, were selected to test the potential anticancer effects of EGCG on esophageal squamous cell carcinoma cells. The tumor-suppressive effects of EGCG against esophageal cancer cells were thus investigated in vitro. The results of an MTT assay demonstrated that EGCG inhibited the viability of Eca109 and Ec9706 cells in a dose- and time-dependent manner. Flow cytometric results indicated that the EGCG also induced apoptosis in Eca109 and Ec9706 cells in a dose-dependent manner. However, the molecular mechanisms underlying EGCG-induced apoptosis in esophageal cancer cells remain poorly understood. In the present study, EGCG was reported to exert cytotoxic effects on human esophageal cancer cell lines in vitro. This cytotoxicity was revealed to be mediated by apoptosis, a conclusion supported by apoptosis detection and expression of the apoptosis-associated protein caspase-3. Apoptosis is involved in the maintenance of cell homeostasis, and dysfunction of apoptotic signaling may result in serious conditions, including cancer.

At present, apoptosis is the most well-studied mechanism associated with anticancer therapy. Apoptosis is cell death under genetic control, involving complicated regulatory mechanisms. Mitochondrial transmembrane potential loss is able to induce apoptosis. In the present study, the pro-apoptotic effect of EGCG on Eca109 and Ec9706 cells was assessed in vitro, with focus on the mitochondrial pathway. The apoptosis rate was detected using Annexin V/PI staining and a flow cytometer. Treatment with various concentrations of EGCG was revealed to promote apoptosis of Eca109 and Ec9706 cells in a dose-dependent manner. The reduction of cell proliferation is associated with apoptosis. Mitochondrial transmembrane potential, an essential effector of the intrinsic pathway of apoptosis, was downregulated following EGCG treatment. Mitochondrial transmembrane potential downregulation is associated with the induction of apoptosis. Caspase-3 protein was upregulated in a dose-dependent manner in Eca109 and Ec9706 cells following treatment with EGCG. In the present study, EGCG induced Eca109 and Ec9706 cell apoptosis by downregulating mitochondrial membrane potential and upregulating caspase-3 expression levels.

Telomerase activity allows eukaryotic cells to have unlimited division potential. While functioning, telomerase synthesizes short DNA repeats at the 3'- end of DNA within chromosomes, ensuring genome stability during cell division. Telomerase is active in the majority of cancer cell types. Meanwhile, telomerase activity is essential for survival of malignant cells. The present study revealed that telomerase activity in Eca109 and Ec9706 cells was downregulated following EGCG treatment.

The specific mechanism inhibiting the growth of esophageal cancer cells by EGCG was explored in the present study. EGCG inhibited cell viability and induced esophageal cancer cell apoptosis, reducing the mitochondrial membrane potential and telomerase activity while increasing caspase-3 expression levels. As EGCG has the characteristics of low toxicity and few side effects, if it can be developed as an anti-tumor drug, it will have broad application prospects.

\section{References}

1. Gamliel Z: Incidence, epidemiology, and etiology of esophageal cancer. Chest Surg Clin N Am 10: 441-450, 2000.

2. Holmes RS and Vaughan TL: Epidemiology and pathogenesis of esophageal cancer. Semin Radiat Oncol 17: 2-9, 2007.

3. Wheeler JB and Reed CE: Epidemiology of esophageal cancer. Surg Clin North Am 92: 1077-1087, 2012.

4. Sugimura K, Miyata H, Tanaka K, Takahashi T, Kurokawa Y, Yamasaki M, Nakajima K, Takiguchi S, Mori M and Doki Y: High infiltration of tumor-associated macrophages is associated with a poor response to chemotherapy and poor prognosis of patients undergoing neoadjuvant chemotherapy for esophageal cancer. J Surg Oncol 111: 752-759, 2015.

5. Cao B, Shi Q and Wang W: Higher expression of SIRT1 induced resistance of esophageal squamous cell carcinoma cells to cisplatin. J Thorac Dis 7: 711-719, 2015. 
6. Liu L, Zuo LF, Zuo J and Wang J: Artesunate induces apoptosis and inhibits growth of Eca109 and Ec9706 human esophageal cancer cell lines in vitro and in vivo. Mol Med Rep 12: 1465-1472, 2015.

7. Yang GZ, Wang ZJ, Bai F, Qin XJ, Cao J, Lv JY and Zhang MS: Epigallocatechin-3-gallate protects HUVECs from PM2.5-induced oxidative stress injury by activating critical antioxidant pathways. Molecules 20: 6626-6639, 2015.

8. Zhao H, Xie P, Li X, Zhu W, Sun X, Sun X, Chen X, Xing L and Yu J: A prospective phase II trial of EGCG in treatment of acute radiation-induced esophagitis for stage III lung cancer. Radiother Oncol 114: 351-356, 2015 .

9. Chen J, Xu J, Li J, Du L, Chen T, Liu P, Peng S, Wang M and Song H: Epigallocatechin-3-gallate attenuates lipopolysaccharide-induced mastitis in rats via suppressing MAPK mediated inflammatory responses and oxidative stress. Int Immunopharmacol 26: 147-152, 2015.

10. Shankar S, Ganapathy S and Srivastava RK: Green tea polyphenols: Biology and therapeutic implications in cancer. Front Biosci 12: 4881-4899, 2007.

11. Thangapazham RL, Singh AK, Sharma A, Warren J, Gaddipati JP and Maheshwari RK: Green tea polyphenols and its constituent epigallocatechin gallate inhibits proliferation of human breast cancer cells in vitro and in vivo. Cancer Lett 245: 232-241, 2007

12. Shin YS, Kang SU, Park JK, Kim YE, Kim YS, Baek SJ, Lee SH and Kim CH: Anti-cancer effect of (-)-epigallocatechin-3-gallate (EGCG) in head and neck cancer through repression of transactivation and enhanced degradation of $\beta$-catenin. Phytomedicine 23 : 1344-1355, 2016

13. Qiao Y, Cao J, Xie L and Shi X: Cell growth inhibition and gene expression regulation by (-)-epigallocatechin-3-gallate in human cervical cancer cells. Arch Pharm Res 32: 1309-1315, 2009.

14. Min NY, Kim JH, Choi JH, Liang W, Ko YJ, Rhee S, Bang H, Ham SW, Park AJ and Lee KH: Selective death of cancer cells by preferential induction of reactive oxygen species in response to (-)-epigallocatechin-3-gallate. Biochem Biophys Res Commun 421: 91-97, 2012.

15. Siddiqui WA, Ahad A and Ahsan H: The mystery of BCL2 family: Bcl-2 proteins and apoptosis: An update. Arch Toxicol 89: 289-317, 2015

16. Aouacheria A, Cibiel A, Guillemin Y, Gillet G and Lalle P Modulating mitochondria-mediated apoptotic cell death through targeting of Bcl-2 family proteins. Recent Pat DNA Gene Seq 1: 43-61, 2007.

17. Shi LS, Wang H, Wang F, Feng M, Wang M and Guan WX Effects of gastrokine-2 expression on gastric cancer cell apoptosis by activation of extrinsic apoptotic pathways. Mol Med Rep 10: 2898-2904, 2014.
18. Shi J, Liu F, Zhang W, Liu X, Lin B and Tang X: Epigallocatechin-3-gallate inhibits nicotine-induced migration and invasion by the suppression of angiogenesis and epithelial-mesenchymal transition in non-small cell lung cancer cells. Oncol Rep 33: 2972-2980, 2015.

19. Irimie AI, Braicu C, Zanoaga O, Pileczki V, Gherman C, Berindan-Neagoe I and Campian RS: Epigallocatechin-3-gallate suppresses cell proliferation and promotes apoptosis and autophagy in oral cancer SSC-4 cells. Onco Targets Ther 8: 461-470, 2015.

20. Tang G, Zhang Z, Qian H, Chen J, Wang Y, Chen X, Chen B and Chen Y: (-)-Epigallocatechin-3-gallate inhibits osteosarcoma cell invasiveness by inhibiting the MEK/ERK signaling pathway in human osteosarcoma cells. J Environ Pathol Toxicol Oncol 34: 85-93, 2015.

21. Bao $\mathrm{H}$ and Peng A: The green tea polyphenol(-)-epigallocatechin-3-gallate and its beneficial roles in chronic kidney disease. J Transl Int Med 4: 99-103, 2016.

22. Khan MA, Hussain A, Sundaram MK, Alalami U, Gunasekera D, Ramesh L, Hamza A and Quraishi U: (-)-Epigallocatechin-3-gallate reverses the expression of various tumor-suppressor genes by inhibiting DNA methyltransferases and histone deacetylases in human cervical cancer cells. Oncol Rep 33: 1976-1984, 2015.

23. Wang J, Xie Y, Feng Y, Zhang L, Huang X, Shen X and Luo X: (-)-Epigallocatechingallate induces apoptosis in B lymphoma cells via caspase-dependent pathway and $\mathrm{Bcl}-2$ family protein modulation. Int J Oncol 46: 1507-1515, 2015.

24. Li YJ, Wu SL, Lu SM, Chen F, Guo Y, Gan SM, Shi YL, Liu S and Li SL: (-)-Epigallocatechin-3-gallate inhibits nasopharyngeal cancer stem cell self-renewal and migration and reverses the epithelial-mesenchymal transition via NF- $\mathrm{B}$ p 65 inactivation. Tumour Biol 36: 2747-2761, 2015.

25. Yang C, Du W and Yang D: Inhibition of green tea polyphenol EGCG ((-)-epigallocatechin-3-gallate) on the proliferation of gastric cancer cells by suppressing canonical wnt/ $\beta$-catenin signalling pathway. Int J Food Sci Nutr 67: 818-827, 2016.

26. Shin YS, Kang SU, Park JK, Kim YE, Kim YS, Baek SJ, Lee SH and Kim CH: Anti-cancer effect of (-)-epigallocatechin-3-gallate (EGCG) in head and neck cancer through repression of transactivation and enhanced degradation of $\beta$-catenin. Phytomedicine 23 . 1344-1355, 2016.

27. Li M, Li JJ, Gu QH, An J, Cao LM, Yang HP and Hu CP: EGCG induces lung cancer A549 cell apoptosis by regulating Ku70 acetylation. Oncol Rep 35: 2339-2347, 2016. 